\title{
The place of complementary studies in an engineering programme
}

\section{J. Molgaard and J. J. Sharp}

\section{A. Harwood, Member, Canada}

I fully support the Authors' position with regard to the study of humanities, social sciences and related topics in an engineering undergraduate program. It seems to me, however, that the details of the complementary studies curriculum could have been more focused. Simply to propose that students study philosophy, history, art, literature, etc., is not sufficient. A clear path has to be shown. Two clues as to how to approach this problem are contained in a quotation by $\mathrm{A}$. H. Rhodes: ${ }^{14}$ " $\mathrm{A}$ professional engineer is competent by virtue of his fundamental education and training to apply the scientific method and outlook to the analysis and solution of engineering problems. ... (1954 EUSEC)'. The phrases 'scientific method' and 'solution of engineering problems' have their roots in philosophy and could provide such a starting point.

60. Philosophers have been studying problem solving for at least 2400 years. Hilary Putnam, in a BBC TV Broadcast in 1978, said: '... scientific method ... goes way back. Newton was sufficiently impressed by the ideas of the philospher Bacon to describe his own method as "induction"'. W. C. Salmon, in his book, The problem of induction, notes: 'We observe that human beings utilize what may be roughly characterized as inductive or scientific methods of extending knowledge...'. Induction is just one of several philosophical methods of problem solving that are worthy of study.

61. George Polya in How to solve it describes a method of problem solving called heuristic, based on the ideas of Descartes, Leibnitz and others. He suggests that there are four essential steps in solving a problem: first, understand the problem; second, devise a plan; third, carry out the plan; fourth, check back to test the validity of the solution. He demonstrates how the most complex problems can be solved using this method. Michael Polanyi, FRS, in his book, Personal knowledge, also discusses heuristic along with power politics, showing how philosphers such as Marx and Machiavelli proposed means of acquiring power based on manipulating the masses. He claims that 'civic culture still remains dependent on force and material ends,...'.

62. Some universities offer courses on problem solving but tend to concentrate on mathematical techniques only. A course on problem solving using heuristic as well as algorithmic methods would be beneficial for engineers.

63. Many of the problems faced by engineers are the result of non-technical influences. Corruption, patronage, politics, shortage of money, poor communications are just some of these. The damage caused by the recent San Francisco earthquake was not the result of engineers not knowing how to allow for the earthquake forces; it was lack of appreciation that these other factors can have a 


\section{DISCUSSION}

direct effect on the performance of a structure. If the collapsed structures had been constructed in accordance with the best technical information available at the time, the damage would probably have been minimal. However, it is not enough to blame the politicians, the public, the budget director or anyone else for the mistakes; it is engineers that are to blame for not understanding the significant influence they can have on a project.

64. To a large extent the engineer has lost control of the projects for which he or she is responsible. The Brunels and the Roeblings had control over their projects. John Roebling, for instance, studied architecture, bridge construction and hydraulics. He also studied philosophy under Hegel. His knowledge came in useful when W. M. Tweed (boss) tried to control the construction of the Brooklyn Bridge. There are many other examples of civil engineers who were also great philosophers. Herbert Spencer was a surveyor and designer of railway lines and bridges. $\mathrm{He}$ is noted for writing about the most difficult of problems in the clearest of terms.

65. Today, our attention is so focused we miss the obvious. Dr Tom Tavares, a Toronto psychologist, says about today's executive: 'Change is on him before he knows it. Forced to react, he has no time to define problems or plan action'.

66. An article in the December 1988 edition of Scientific American describes the achievements of the canal builders of pre-Inca Peru. The difficulties experienced by these Chimor engineers of 1000 years ago are remarkably similar to those of today. If only they could have learnt from the Roman engineers of 2000 years ago. Perhaps we could learn from both of them!

67. Samuel Florman, in The existential pleasures of engineering, wrote: "Each new achievement discloses new problems and new possibilities'. Let us ensure that we have the capabilities to solve them.

\section{Rathbone, Fellow}

While the Paper may have been aimed initially at an academic audience, it is directly relevant to employers in engineering construction and manufacture.

69. The poor status of the UK engineering profession reflects the cultural climate in which Victorian standards marked the differences between 'trade' and 'gentry', the latter being a class whose practical interests were strictly dilettante. The logical outcome of this was epitomized eventually in the recruitment and promotion practices of the UK civil service. For many years, the professional views of engineers, architects and economists were expressed at the executive level, but policy making was confined to administrative officers, the vast majority of whom were high-flying arts graduates. The rationale behind this was that a good trained mind, free from the limitations of a narrow technical discipline, would easily comprehend technical matters and be able properly to discriminate between conflicting technological arguments. It is hardly coincidental that the decline in UK economic strength vis-à-vis Continental Europe occurred while this view held sway. The type of broader education described here would qualify engineers to perform a wider role in society and, in due course, would rectify the present undesirable situation.

70. Although Table 1 is compiled from a 1979 US survey, its findings will certainly be echoed today by UK management. Even at the base level of graduate engineering employment, the ability to communicate will have some importance. Above this level, such skills become more and more necessary to engineers who are 
to form part of a management team. As long ago as 1916, Henri Fayol identified no more than nine levels of authority between the Head of State and the shop floor operative, and set down the managerial, technical and other skills appropriate to each level. In the intervening 75 years, theories of both management and technology have advanced, but Fayol's analysis still holds good. Irrespective of the level of professional responsibility, at one extreme e.g. R\&D worktechnological ability will account for perhaps $80 \%$ of the job specification; at the other, no more than $15 \%$ of the requisite abilities of a general manager will lie in technology while the proportion of management skills rises from $15 \%$ to $60 \%$.

71. It is to be noted that the limitations referred to in $\S 9$ are not confined to professional engineers. Many professional accountants, while entirely competent in taxation, fiscal or costing operations, are nevertheless unable to contribute to the strategic or tactical planning of the business in which they are occupied. However, the fact that, in UK industry at least, there are more chief executives with financial rather than engineering backgrounds is probably not related simply to the importance of the financial operation in determining the viability of the enterprise; it is likely to reflect a wider range of interests and better communication skills. A similar situation can be seen in North America but with the emphasis on legal rather than accounting qualifications.

72. From the employer's point of view the arguments of $\S 8$ are entirely comprehensible. Subject to a definite minimum, any technical deficiency resulting from a curtailed engineering course of study is recoverable in post-graduate employment. There is indeed an arguable case to make that the course content of a first degree is anyway highly limited in its subsequent utility, and that the engineer's technical education will not be adequate until he/she reaches the level of membership of his/her professional institution. If this is right, time lost to undergraduate technical studies is less important than the gain in broader outlook arising from complementary studies. A graduate engineer with some education in the humanities is likely to expand his/her interests in later life; many of those without this wider education will never develop into those interests.

73. The UK position, where three-rather than four-year courses are the norm, is no less critical. In some academic circles, the emphasis on technical topics is taken to the stage where the objective appears to be to endow all graduates with a deep-rooted and complete knowledge of the appropriate technology. Necessary though such skills are, there remains a requirement in industrial life for lettuces as well as carrots. It may well be that a graduate engineer with a broader outlook will be more effective than one possessed of narrower, more comprehensive technical skills, the more so since the latter will in any event become obsolescent over time. Would the Authors agree that there is a law of diminishing returns in technical education, and that beyond a certain point in first degree courses, time spent in advanced engineering study is time which could be better used elsewhere?

74. The practice of $\$ 51$ and 53 will certainly concentrate the student mind, but, in view of the importance of communication skills, have the Authors reconsidered the desirability of including some minimal formal instruction in this topic? The assistance of external moderators in assessing the final year project could be of value to both students and faculty; is such assistance provided? The complementary studies programme has now been operative for more than 20 years-sufficient time for a track record to be established. Can the Authors present any evidence, anecdotal or otherwise, on the post-graduate experience of their students and on the success rate which has attended them? 


\section{DISCUSSION}

\section{Professor Molgaard and Professor Sharp}

We can only agree with $M r$ Harwood that problem solving is at the core of engineering, and that many of the problems faced in engineering practice have a non-technical component: i.e. political, economic, or social dimensions. Ashby, whom we have already quoted in our Paper, ${ }^{12}$ pointed out that the civil engineer who builds a road into a new territory in tropical Africa is, in fact, conducting a major experiement in social anthropology. Road building can have the same effect in Newfoundland, where until recently many communities were not connected to the main road network, and there are still a few communities isolated in this way.

76. Some student groups have studied the effect of road building and other improvements in communications in the project course, Assessment of technology, described in our Paper, and have noted the social effects of the improved access to and from the outside world. However, this project course and indeed all of the courses considered to be 'complementary studies' do not have problem solving as an objective. It is sufficient that the students use these lecture and project subjects as opportunities for analysis of the problems, since problems involving social dimensions are big enough, and the social dimensions significant enough, that students should use all the time they have in complementary studies to gain as deep an understanding as they can of these aspects, without attempting also to develop a solution; although students are often tempted to propose solutions, since they are used to that from several technical courses.

77. In our experience, when students are permitted to consider solutions to this kind of problem in Assessment of technology, the solutions tend to be too facile, or simply to reflect the solutions suggested to them by informants who may be using the students as mouthpieces, and the students do not have the time to develop and evaluate several alternatives as well as they should.

78. This is not to suggest that the Faculty of Engineering at Memorial University does not take education in problem solving very seriously, and we are aware of the views of a number of the authorities referred to by Mr Harwood. One of us has already described this aspect of our programme in some detail. ${ }^{15,16}$ Problem solving is dealt with in the context of design, initially, at an early stage in groups faced with simple problems of a classical type, which encourage the use of ingenuity in the use of simple construction materials.

79. Later, students in civil engineering work on complex problems more typical of engineering practice, with practising engineers acting as clients, with an introduction to elements of systems analysis.

80. Mr Rathbone asks whether or not we provide minimal formal instruction in communication. We have considered the introduction of one lecture course in written and oral communication: i.e. typically a course involving the students for three hours a week for twelve weeks. This has never been adopted in this Faculty, as all students are required to write a number of major reports at the end of each of six work terms and in a number of technical courses, as well as in complementary studies, and so already have to spend an appreciable time at written communication; most achieve a good standard by the time they graduate.

81. The work report requirements in the work terms are laid down in the University Calendar, in the description for the work term, and so are formal in that sense, and the requirements are enforced by the Faculty. Students who have difficulty meeting these requirements are given guidance and coaching.

82. Some guidance and exercise in oral communication is given to students in 
small groups in Communication Workshops, held throughout the fifth academic term. This involves each student for about three hours in one week of that term, in which a presentation by the student is recorded on videotape and viewed by the student and instructor, who provides comments and advice. There are several other occasions in the programme when each student has to give a presentation.

83. Mr Rathbone also asks if we have any evidence on the effect of our programme in complementary studies. We can mention that many of the people whom the students have consulted in the Assessment of technology project course, have expressed their appreciation of and admiration for the reports produced. Several consultants have used these reports in their own work, since the engineering students have often been the first to examine the topics in question. As mentioned in our Paper, several such reports are now a valued resource in the University Library and elsewhere.

84. Many employers of our undergraduates on work terms, and of our graduates, have also commented on the rapidity and confidence with which many of our students and graduates accept and master the new challenges faced in their jobs. If this is so, more than one part of the programme, of which the co-operative aspect must be emphasized, must make the difference. The six work terms and the associated structure, with a report and an evaluation of performance required each work term, must contribute a great deal to the student's ability to deal with the real world.

85. Some of our graduates are involved in environmental impact assessment and control, in government, consulting, and industry, and will have acquired the basis of their knowledge in this area through the complementary studies programme. Several have, on occasion, returned to the University to lecture in the complementary studies component on their current work. We have no doubt from our experience, that our senior students are both ready and able to accept the challenges engineers face in this area.

86. It is not easy to document any difference that complementary studies have had at the postgraduate stage, just as one cannot readily point to examples of the postgraduate exercise of any other particular skills taught at the undergraduate level, except perhaps the more trivial or obvious ones, such as drafting or computer skills, or the preparation of professional reports. It would also in any event be presumptuous to attribute any positive attributes in our graduates, such as an awareness of social issues, to our programme, if indeed we could somehow establish that these attributes exist. One can only hope that our efforts have not been in vain, and let the graduate engineers take the credit themselves for their good qualities. In the final analysis, that is as it should be.

\section{References}

14. RHODES A. H. Discussion on Paper: ' Professional training and status of civil engineers'. Proc. Instn Civ. Engrs, Part 1, 1973, 54, May, 347-376.

15. Camprell W. J., Christian A. J. and Sharp J. J. Education for professional practice. Proc. Instn Civ. Engrs, Part 1, 1983, 74, Feb., 61-77.

16. SharP J. J. Methodologies for problem solving: an engineering approach. Proc. Instn Civ. Engrs (to be published). 